\title{
多指を用いた視覚障害者支援用触覚ディスプレイ開発のための 基礎研究*
}

\author{
松本悟志**, 嶋脇 聡**, 酒井直隆**
}

\begin{abstract}
The aim of this study is intended to present the basic research necessary to transmit graphic tactile information for helping visually handicapped persons, using a small number of stimulated pins. The tactile display developed in this study has an 80 -pin array $(8 \times 10$ pins $)$. A solenoid is used as an actuator for moving the pins upward. By placing the fingers of both the hands, except the thumb, on the tactile display containing the array of active pins, a subject can obtain the information presented on the display. Five blind subjects and 10 sighted subjects participated in this study. First, the optimum condition for the presentation of the images is determined. Next, the correct answer rates of the character information transmission test before and after a preliminary practice session are compared. The result suggests that the tactile sense of the blind subjects is considerably more sensitive than that of the sighted subjects. Moreover, the correct answer rate increased remarkably after the short time preliminary practice session, indicating that the tactile display is an effective medium for the transmission of tactile information.
\end{abstract}

本研究は, より少ない刺激ピン数で触覚情報を視覚障害者に伝達するために必要な呈示方法の基礎研究を 目的としている. 本研究では，10行×横8列の合計 80 ピンの触覚ディスプレイを試作した。そのピン動力源 としてソレノイドを用いた，母指以外の8指をディスプレイに置き，動作したピンを感じ取ることにより， 呈示された触覚情報を読み取ることができる，視覚障害者 5 名と晴眼者 10 名を対象に本装置の評価を行った。 はじめに，呈示方法の最適条件を求めた。次に，文字情報伝達を学習前と学習後でどの程度正答率に差が出 るかを求めた，測定結果より，視覚障害者は晴眼者と比較して，触覚認識能力がかなり敏感であることが示 された。また，文字情報測定において，短時間の学習後に著しく正答率が上がることから，本研究で試作し た触覚ディスプレイは，触覚情報の伝達に有効である可能性を示唆した。

(キーワード：触覚ディスプレイ, 視覚障害者, 電子点字装置, 触覚インターフェイス)

\section{1.はじめに}

厚生労働省が 5 年毎に実施する身体障害児・身体障害 者等実態調査 ${ }^{1)}$ においての平成 18 年度の報告によると， 国内の視覚障害者・視覚障害児の合計は約 30 万 5800 人で ある.この人数は, 全身体障害者数の約 1 割を占め, 現在 も増加傾向にある。しかし, この調查における回答で全 視覚障害者の内「点字ができる」と答えたのは，わずか $12.7 \%$ (4万 8000 人）でしかない.これは視覚障害の原因 で最も多いのが糖尿病であり, 中途失明者の数が圧倒的 に多いことが理由として考えられる。これより, 中途失 明者であっても容易に情報が得られる支援機器の開発が

\footnotetext{
*受付：2011年4月13日＼cjkstart受理：2011年9月9日

**宇都宮大学工学部機械工学科

Department of Mechanical Systems Engineering, Utsunomiya University
}

求められている。一般に視覚の代行感覚として用いられ るのは，聴覚，触覚である。近年パーソナルコンピュー タ，インターネット通信の普及により，視覚障害者も音 声あるいは，触覚を用いた電子点字ディスプレイ，触覚 ディスプレイなどにより電子情報を容易に得ることがで きるようになってきた。しかしながら現在，一般的に多 用されている触覚を用いた支援機器に関しては，点字を 構成する呈示面を，能動的になぞって読む方式である. この方式は従来の点字を読むことができない人に対して 情報伝達が困難であり普及に至っていない2)。そこで本研 究では中途失明者であっても容易に文字情報・画像情報 が得られ，量産時に低コストになる可能性がある触覚デ イスプレイの開発に必要な触覚刺激の呈示方法について の基礎研究を行った。

触覚ディスプレイとは, 視覚障害者に触覚で困形情報 を伝えるディスプレイ装置である。パソコンを用いて文 字の形や画像を平面上の突起や刺激で伝える。ピンを格 
子状に配列して，それらを上下させて突起（パターン） を形成する, あるいは空気圧を用いる方法, 電気的刺激 によって触覚を生じさせる方法, 神経に直接インターフ エイスする方法などがある ${ }^{3)}$. 古くはカメラで取得した文 字形状を指先に呈示するOPTACONに始まり, 数多くの 研究が行われてきた4).

触覚ディスプレイには情報の伝達方法の違いにより， ダイナミック型（受動的触知）とスタティック型（能動 的触知）の 2 種類に分けられる ディスプレイは皮膚に固定した状態で利用する受動的触 知のディスプレイである。それに対してスタティック型 はディスプレイ上に呈示された静止文字，画像情報を指 先や掌を自由に動かして触り情報を得る能動的触知によ るディスプレイである. 特徴として, ダイナミック型は ディスプレイ上を手で走査させる必要がないため小型化 が可能である。しかし情報伝達精度はスタティック型と 比べて低く，確実に情報を伝えるために振動信号や点運 動信号が使われている。スタティック型の特徴は情報伝 達精度が高いが，ディスプレイ上の情報量を増やすため にはディスプレイ自体を大きくする必要がある。現在， 実用化されている触覚ディスプレイの多くが大型で持ち 運びが困難なスタティック型の触覚ディスプレイである. そこで本研究では小型軽量化が可能であるダイナミック 型の触覚ディスプレイの開発を行い, 問題点である情報 伝達精度を高めるために呈示条件の検討実験を行った。

\section{2. 実 験}

\section{2-1. 実験装置}

現在までに様々なアクチュエータを用いた触覚ディスプ レイの研究が行われてきた.ソレノイド, モータ, 圧電素 子, 形状記憶合金, 空気圧, 水流, 超音波モ一タ, 電気刺 激を与える電極式など様々なものがある ${ }^{4,6}$. しかし現在, 小型軽量化，低価格化，保守性など様々な問題が克服さ れておらず普及に至っていない，本研究で目標としている ダイナミック型の触覚ディスプレイには電気刺激によるも のが多い，電極による電気刺激は，応答性，可搬性，価格 の面で優れている。しかし多くの文献において不快感, 安 全性に問題があることが指摘されていることより今回は除 外し, 現状最も安価に入手できるソレノイドをアクチュエ 一タとして選択した ${ }^{7,8}$. ソレノイドとは電磁力によって鉄 心が駆動するアクチュエータである。特徴から微小駆動用 として使われる，コイル内に可動鉄心を設置し，電流を加 えることで直進運動を得ることができる。

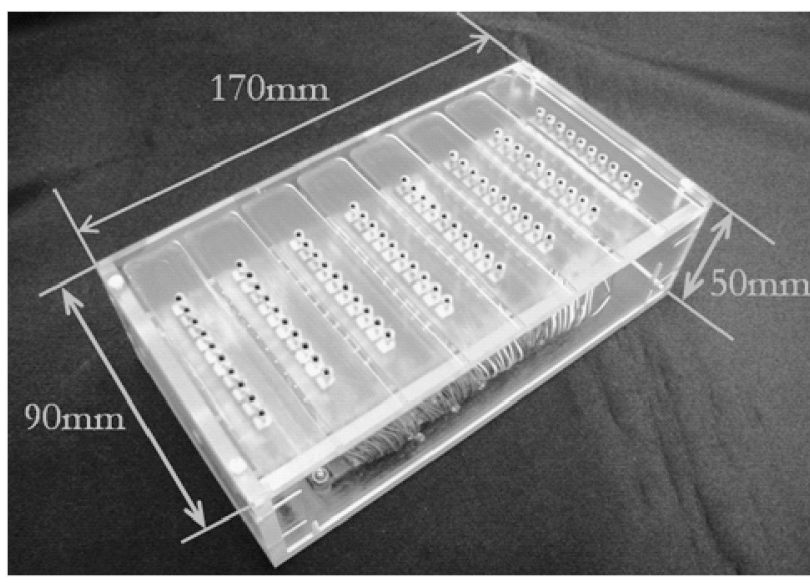

図 1 触覚ティスプレイ写真

Fig. 1 Picuture of the tactile display.

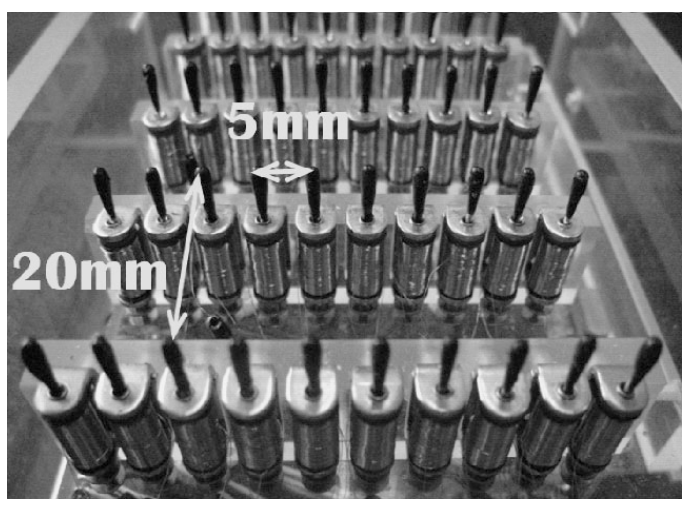

図2 触覚ディスプレイのピン

Fig. 2 Pins of the tactile display.

図1のようにピン配置は，両手の母指以外の8指にそれ ぞれピンを 10 ピンずつ，計 80 ピンとした．また，配置ピ ッチ比率は，縦横それぞれ $1 ： 4 （ 5 \mathrm{~mm}: 20 \mathrm{~mm})$ とな る。ディスプレイ表面に両手の指を固定した状態で使用 するメリットの一つとして，受動的に刺激を得られると 共に，連続的な刺激を伝達可能となる点がある。また， 等ピッチでピンを配置したと仮定した場合， $10 \times 8 \times 4=$ 320 本の動作ピンが必要となり，アクチュエータ数が $1 / 4$ でも，触覚情報伝達能力に問題なければ，刺激可動部の コストが $1 / 4$ となることを目指す

また，この配置方法はLED等を用いた電子公告表示機 で実用化されており，少ない光源数にも関わらず，視覚 の残像効果を利用して，スクロール表示に限定されるが フルスクリーン表示と遜色ない表示機が実用化されてい る. 今回，この表示方法が触覚でも応用できないかも検 討の一つとなっている ${ }^{9)}$.

触覚を刺激するソレノイドピンの先端が細いと，ピン先 が接触した際に痛みを感じてしまう恐れがある。よって， 木塚 ${ }^{10)}$ の報告に打いて一般的に紙点字の直径は $1.5 \mathrm{~mm}$ 前 


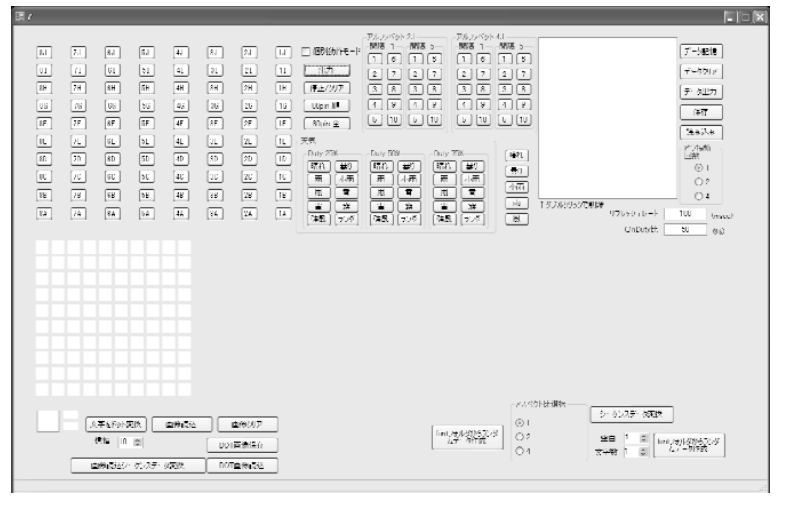

図3制御ソフト

Fig. 3 Control software.

後と報告されており，本装置で採用したソレノイドのピン 径は $0.7 \mathrm{~mm}$ 程度であったため，図2のように樹脂コーティ ングを行い，ピンの先端を丸く，かつ，ピン径が $1.5 \mathrm{~mm}$ 前後になるように調整した。 また, 先の研究11) により刺激 強度は $90 \mathrm{mN}$ になるようにソレノイドの電圧を調整した。 また，呈示データはPCより，図3の制御ソフトを作成し ディスプレイに呈示データを転送する方式で実験を行う。

\section{2-2. 実験手法}

\section{2-2-1. 被験者}

被験者として手に外傷，疾患の既往歴のない $21 ２ 3$ 歳 の男性健常者 10 人，同様に手に外傷，疾患の既往歴のな い 28 歳 58 歳の全盲の視覚障害者, 男性 3 人, 女性 2 人を 選んだ．全盲の被験者 5 人は栃木県立盲学校の教職員であ り, 点字暦が 17 年以上で点字読に熟達している. Satoら の報告 ${ }^{12)}$ に打いて男性 357 人と女性 184 人の触点の分布密 度を求める実験を行っている。結果に扎いて男性は 25.0 $\pm 0.5 / \mathrm{cm}^{2}$ ，女性は $24.3 / \mathrm{cm}^{2}$ ということが明らかになり， 触覚に男女の有意な性差は無いことが示されている。よ って, 視覚障害者の被験者に関して本実験では男女の結 果は同一の条件として評価した。また，ランドルト環の 識別実験は晴眼者のみで行った。

\section{2-2-2. 実験対象部位}

本実験における測定対照部位は, 晴眼者, 視覚障害者 共に母指以外の両手 8 本の指である. 測定対象部位を図 4 に示す。

\section{2-3. 実験 1ーランドルト環の識別実験}

本研究により試作した触覚ディスプレイを用いて, 図 5に示す視覚検査に用いられるCの形をしたランドルト環 を呈示し, そのC形の切り欠き方向を識別する実験を行 う。この実験の目的は，文字の呈示を左から右へ移動し た場合, 認識可能な隙間方向と大きさを調査することに

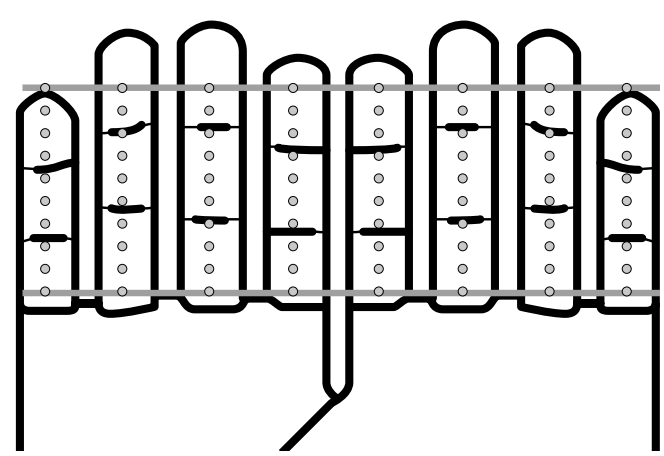

図4 測定対象部位

Fig. 4 Experiment part of the fingers.

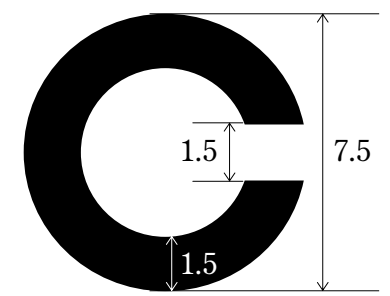

図5 視覚検査に用いられるランドルト環（数值は寸法比）

Fig. 5 Landolt ring used for eye examination (The value is dimensional ratio).

ある。すべての実験において，呈示間隔（リフレッシュ

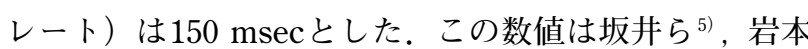
ら 13)によるデータより，明らかに独立刺激となる時間領 域である $200 \mathrm{~ms}(5 \mathrm{~Hz})$ ，及び，なぞるような連続した刺 激感になる時間間隔である $100 \mathrm{~ms}(10 \mathrm{~Hz})$ の中間值と して選択された。

両手の母指を除いた 8 指に 10 ピンずつの計 80 ピンを用 い(図6)，呈示したランドルト環は上下左右の4種で，ピ ン配置の都合より斜め方向の呈示を実施しなかった。方 法として，まず被験者に，各条件におけるランドルト環 を2回ずつ呈示し認識してもらう。そしてランダムに一つ のランドルト環を呈示し，環の開いている方向を答えて もらう。これを，ランドルト環の大きさ，アスペクト比 (画像の縦横の比), 刺激回数を変えた各条件で行った。 呈示したランドルト環のサイズ大中小は，隙間と文字高 さの比率がランドルト環 $1.5 ： 7.5$ に最も近くなるよう，そ れぞれ $4: 10 ３ ： 7 ， 2 ： 6$ とした。また，ランドルト環 の比率とは完全に一致しないが，ヒ卜触覚の分解能は僅 かな差を認識することが困難なため問題ないと考える. 各呈示において正解は非通知とした。実験に際しては， 閉眼状態で触覚ディスプレイに対し正面に座り，認知で きない場合は「分からない」と回答するように指示した。 Vega ${ }^{14)}$ によるパターン識別実験において，1時間以内 の実験では学習能力により，平均して4\%の正答率の向上 


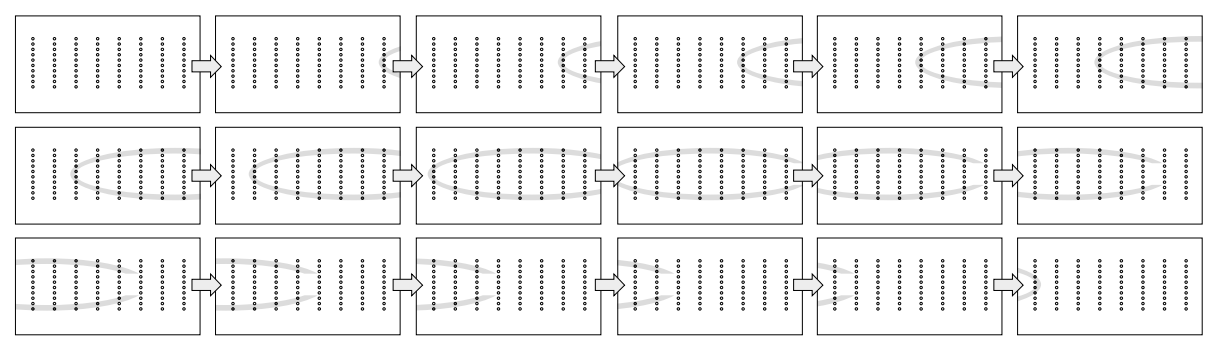

Size: Big - - - Height is 10 pins. C gap is 4 pins.

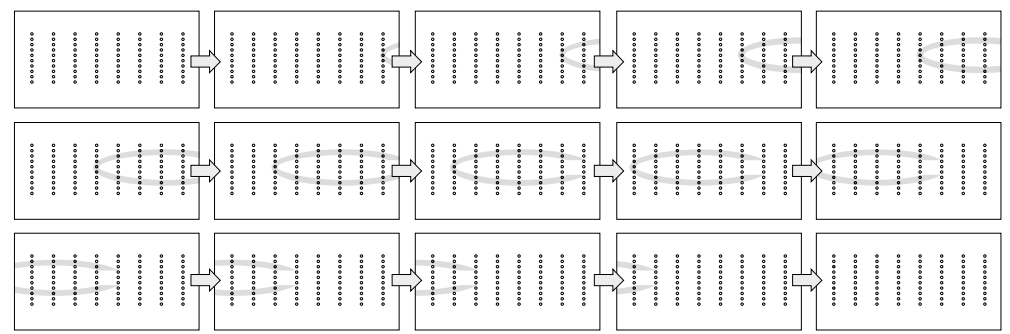

Size: Medium - - - Height is 7 pins. C gap is 3 pins.

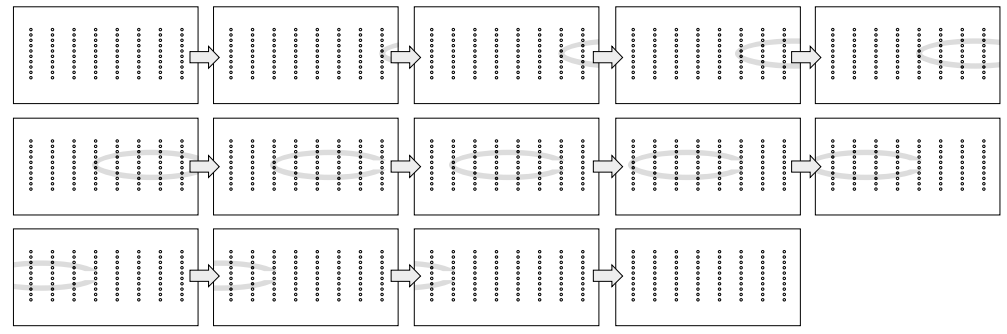

Size: Small - - - Height is 6 pins. C gap is 2 pins

図6 ランドルト環呈示の例（アスペクト比 4：1）

Fig. 6 The example of Landolt ring presentation (Aspect ratio [4:1]).

が報告されている，よって本研究で条件を変えての実験 にあたり, 先行条件における影響軽減のため, 異なる課 題の実施は1日以上の時間を空けて行った。

\section{2-4. 実験 2 -アルファベットの認識実験}

次に,アルファベット 26 文字の認識実験を行う。試作し た触覚ディスプレイでの文字情報呈示の可能性と最適条件 を調査する. 本実験も呈示間隔は同様に $150 \mathrm{msec}$ とす。.

アルファベット 26 文字から無作為に3文字を選択して, それらで文字列（実際の呈示例：XGX, PHT, KWQ, $\mathrm{UGH}$ ……など）を構成した。両手の母指を除いた8指に 10 ピンずつの計 80 ピンを使って, この文字列を右から左 に流れるように呈示して，この文字列を回答してもらっ た．各呈示において正解は非通知とした。本実験で用い たフォントを図7に示す，呈示条件として，文字間隔，文 字アスペクト比（画像の縦横の比）とした。さらに簡単 な基礎学習の効果も調查した.

栗田の視覚特性の報告 ${ }^{15)} に$ 扎いて, 文字間隔は文字の 0.2 0.5倍が最も読みやすいと報告されている. また，今 回, 多くの文字は10列で構成されているので, 視覚特性

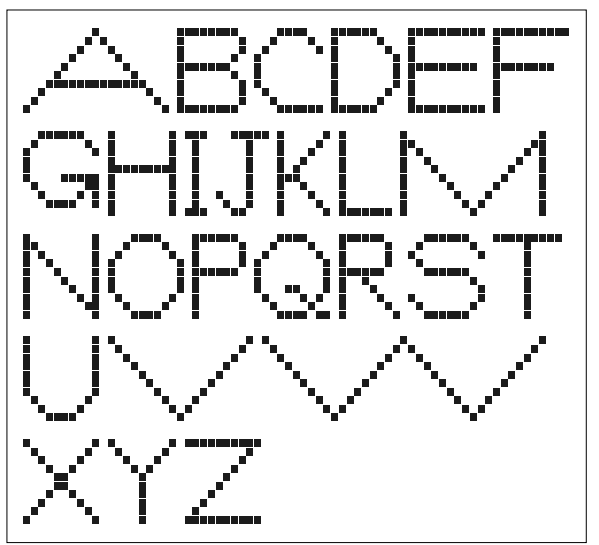

図7 フォント一覧（高さ10）

Fig. 7 The font list (the height is 10).

と触覚特性が比較できるように，文字の間隔として，1列 と5列の 2 種類とした。文字アスペクト比として，4:1と $2: 1 の 2$ 種類とした。実験条件に再度アスペクト比を追 加した理由として，画像ではなく文字に扔いての条件を 確立するためである．簡単な基礎学習（10分程度）の影 響を調査した。基礎学習とは，A〜Zまでを一文字ずつ確 認し，最後に気になる文字を再度確認してもらった。 
実験状態に関しては，閉眼状態で触覚ディスプレイに 対し正面に座り, 認知できない場合は「分からない」と 回答するように指示した. また, この実験も学習能力に よる影響軽減のため, 異なる課題の実施は1日以上の時間 を空けて行った。

\section{3. 結 果}

\section{3-1．実験 1ーランドルト環の識別実験}

\section{3-1-1. ランドルト環の大きさにおける比較}

ランドルト環の大きさにおける比較結果を困8に示す. ランドルト環（大）とランドルト環（小）の正答率にお いて，ランドルト環（大）の方が, 有意に正答率が高か った $(\mathrm{p}<0.01)$ 。また，ランドルト環（中）とランドル 卜環（小）の正答率に扎いて，ランドルト環（中）の方 が，有意に正答率が高かった $(\mathrm{p}<0.05)$.

\section{3-1-2. 文字アスペクト比における比較}

文字アスペクト比における比較結果を罒9に示す。文字 アスペクト比 $2: 1 と 4: 19$ 正答率においては, 文字アス ペクト比 $2 ： 10$ 方が，有意に正答率が高かった（ $<<0.01)$. また，文字アスペクト比 $2 ： 1$ と $1 ： 1$ の正答率において

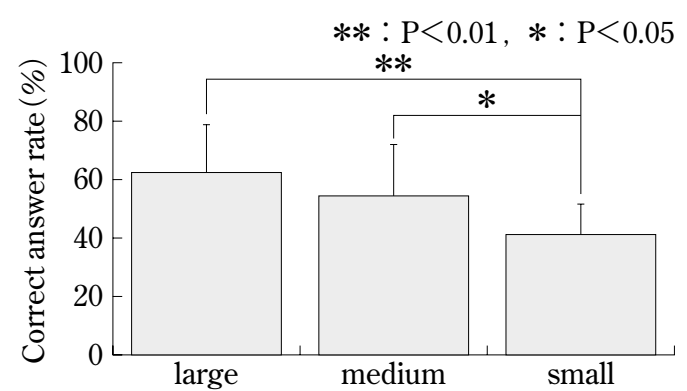

図8 ランドルト環の大きさ別の正答率（エラーバーは標準 偏差を示す)

Fig. 8 The correct answer rate of each Landolt ring size (error bar:SD).

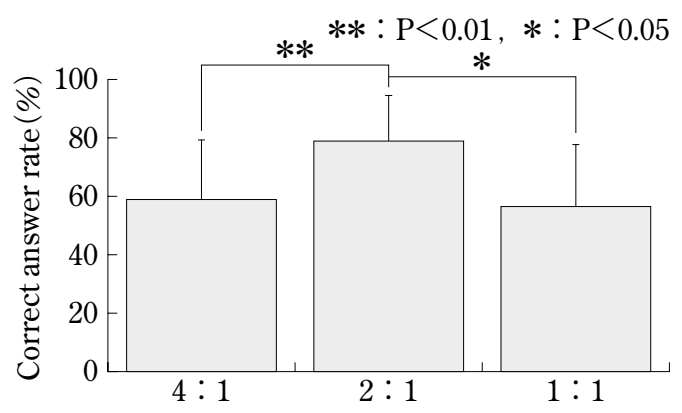

図9 アスペクト比別の正答率（エラーバーは標準偏差を示す）

Fig. 9 The correct answer rate of each aspect ratio (error bar: SD).
は，文字アスペクト比 $2 ： 10$ 方が，有意に正答率が高か つた $(\mathrm{p}<0.05)$.

\section{3-1-3. 刺激回数における比較}

刺激回数における比較結果を図10に示す。ここで刺激回 数とは呈示間隔 $150 \mathrm{msec} て ゙$ 刺激する回数を表し，たとえば 刺激回数 4 回とは，同じ呈示データを 4 回連続で， 150/4= $37.5 \mathrm{msec}$ ごと刺激させ，刺激位置の遷移を行わせることを 意味する。本結果における有意差は見られなかった。

\section{3-2. 実験2ーアルファベットの認識実験}

\section{3-2-1. 文字アスペクト比と文字間隔の比較}

基礎学習前における晴眼者 10 人と視覚障害者 5 人の結 果を図11に示す。文字アスペクト比 $2 ： 10$ 文字間隔1列 および文字アスペクト比 $4 ： 10$ 文字間隔1列の呈示方法 において，視覚障害者の正答率が晴眼者より有意に高く なった $(\mathrm{p}<0.05)$.

\section{3-2-2. 基礎学習前後での比較}

文字間隔5列の呈示方法において，晴眼者および視覚障 害者の基礎学習前後の比較をそれぞれ図12と図13に示 す。どちらの対象も文字アスペクト比にかかわらず有意 に学習の効果が得られた $(\mathrm{p}<0.05)$.

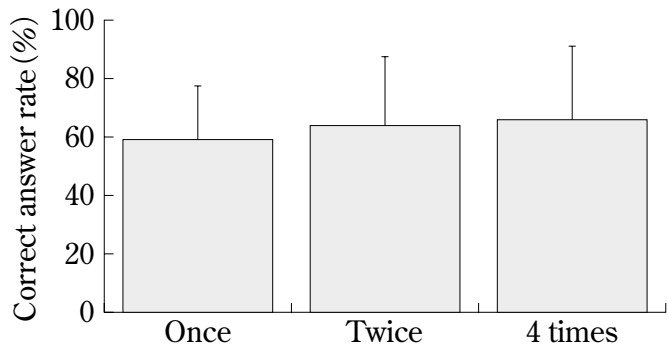

図 10 刺激回数別の正答率（エラーバーは標準偏差を示す）

Fig. 10 The correct answer rate of each stimulation frequency (error bar : SD)

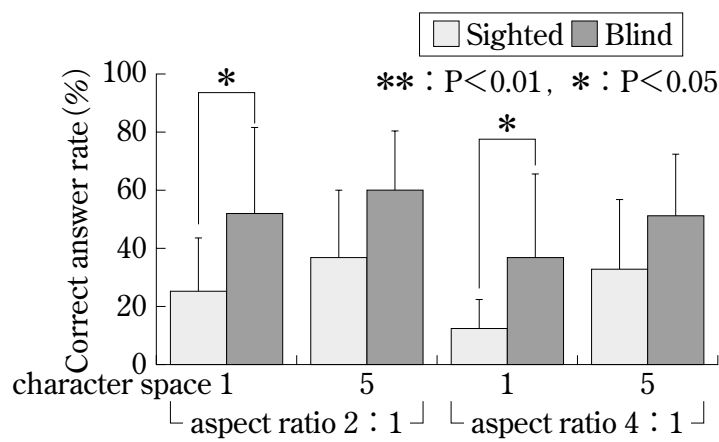

図11学習前のアスペクト比と文字間隔の比較（エラーバ 一は標準偏差を示す)

Fig. 11 The correct answer rate of each aspect ratio and character space before preliminary practice (error bar: SD). 


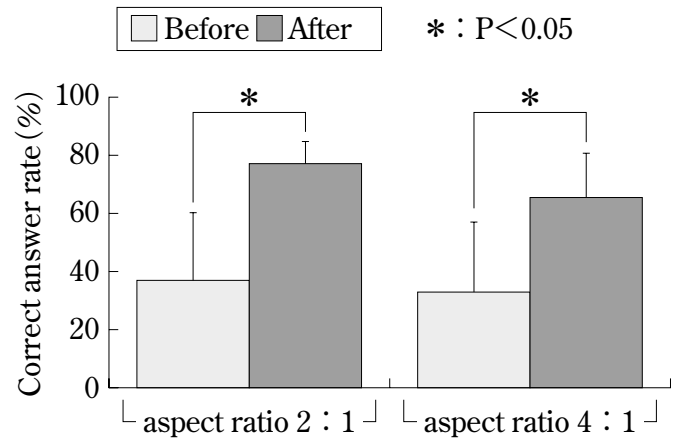

図12 晴眼者のアスペクト比と学習前後それぞれの正答率 (エラーバーは標準偏差を示す)

Fig. 12 The correct answer rate of each aspect ratio and before-and-after practice to sighted subject (error bar:SD).

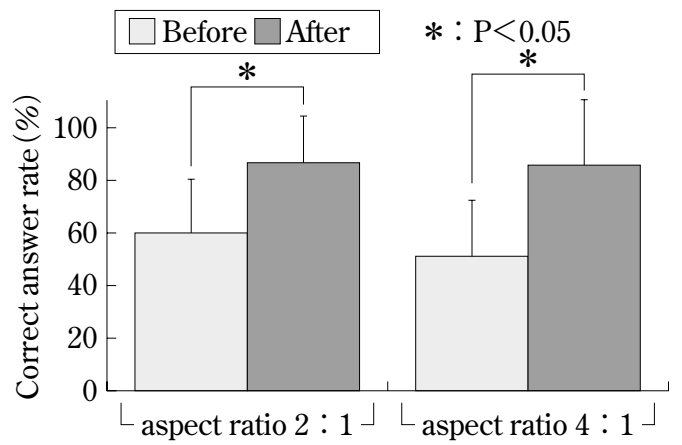

図13視覚障害者のアスペクト比と学習前後それぞれの正 答率（エラーバーは標準偏差を示す）

Fig. 13 The correct answer rate of each aspect ratio and before-and-after practice to blind subject (error bar : $\mathrm{SD})$.

\section{4. 考 察}

\section{4-1. 実験 1ーランドルト環の識別実験}

\section{4-1-1. ランドルト環の大きさ}

ランドルト環の大きさ（大）（中）（小）それぞれのラ ンドルト環Cの隙間のピン数はそれぞれ $4,3,2$ ピンとな っており，図7から，3ピン以上の隙間なら触知すること が可能だが， 2 ピンの隙間になると触知が難しくなるとい うことがわかった。試作した触覚ディスプレイでは，各 ピンの間隔が $5 \mathrm{~mm}$ であった。これは, Nakada' ${ }^{16)} に よ り ，$ 指末節の 2 点識別距離が $3 \sim 5 \mathrm{~mm}$ となっていることが報 告されており， $5 \mathrm{~mm}$ の隙間である 2 ピン分の無刺激部分

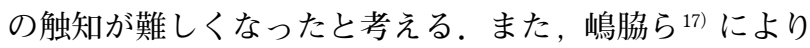
末節部と基節部では $2 \mathrm{~mm}$ 程度の触覚分解能の差があるこ とを示されている。よって, 試作した触覚ディスプレイ ではピン間隔 $5 \mathrm{~mm}$ であったため呈示位置により正答率に
大きな変化はなかったと推定する，しかし，より高密度 の触覚ディスプレイで実験を行う場合，呈示位置により， 正答率が変化する可能性があると思われる.

\section{4-1-2. 文字アスペクト比}

図8より, 文字アスペクト比 $2 ： 1$ が本研究で試作した 触覚ディスプレイにおいて画像呈示の最適条件であった。 脳で触覚情報から文字イメージを再現されていたと仮定 すると, アスペクト比 $1 ： 1$ が通常の視覚イメージと同じ てあるため, 最も認識しやすいと考えていたが，本研究 で試作した触覚ディスプレイでは，ピンピッチが縦 $5 \mathrm{~mm} \times$ 横 $20 \mathrm{~mm}$ であったため, 一度突起した列が次の列

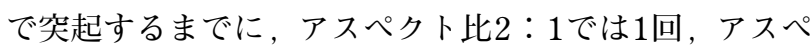
クト比 $1 ： 1 て ゙ は 3$ 回の無刺激が発生する。つまり, 呈示 された列のイメージが残っているかどうかが重要になっ てくる．また，林18)により，皮膚感覚（触覚）において も運動残効考現象が生じることが報告されている。つま り，視覚と同様，触覚に打いても，刺激残像が残るとい うことである。このことから，アスペクト比が $1 ： 1 に$ 近 づけば近づくほど認識し易いが，一度刺激した刺激列が 次の刺激列で刺激動作するまでの3回分までは残像が残り 難いということになる．本装置の刺激ピンの配置条件に おいては，以上の理由により刺激残像が残りやすい $2: 1$ が最も触知しやすい結果に繋がったと考えられる.

\section{4-1-3. 刺激回数}

刺激回数における有意差は見られなかった。しかしな がら, 多くの被験者から, 刺激回数が増えるほど触知し やすいという意見があった．図9より刺激回数が増えるほ ど正答率が上昇する傾向がみられた。しかしながら，有 意差がみられなかったのは, 正答率が比較的高いランド ルト環の大きさ（大）のみで実験したことに起因すると 考える.

\section{4-2. 実験2ーアルファベットの認識実験}

\section{4-2-1. アスペクト比と文字間隔の比較}

アスペクト比 $2: 1$ と $4: 1$ の正答率の検定を行うと, ア スペクト比 $2: 1$ が $4: 1$ よりも有意に正答率が高い結果が 得られる。これはランドルト環の識別実験と同様の結果 になった。本研究で製作した触覚ディスプレイでは，C

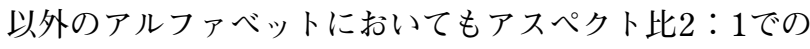
呈示が適していることがわかった。また，図11より，間 隔 5 列が 1 列よりも有意に正答率が高い結果が得られた。 これは文字列の文字間隔が離れると一つ一つの文字の触 知がより正確にできたと考える。一方，栗田 ${ }^{15)} に よ り ，$ 文字間隔は文字サイズの $0.2 \sim 0.5$ 倍が最も読みやすいと いうことが報告されている。 今回作成したフォントは高 
さ10, 横幅平均約 11 のプロポーショナルフォントとなっ ており，文字間隔5列と1列のデータだけでは視覚特性と の差異を単純に比較することはできないが, 視覚特性と 同様に触覚特性においても認識率を上げるためにはある 程度の文字間隔が必要だと考える。

\section{4-2-2. 基礎学習前後での比較}

どの結果においても基礎学習後の正答率が有意に高い という結果を得た。 また視覚障害者において基礎学習後, 全問正解が 2 人，残り 3 人が正答率 2 倍以上になるという 結果が得られた。晴眼者においても基礎学習後, 正答率 が2倍以上になり, 基礎学習前では視覚障害者との間にあ った正答率の有意差を埋めてしまった，触覚において文 字を認識するのに最低1週間程度の学習が必要であると報 告されている ${ }^{19)}$. しかし, 今回試作した触覚ディスプレ イは10分以内の簡単な基礎学習でこのような結果を得る ことができた。このことから，中途失明者が呈示された 文字を認識することができるだけでなく, 先天性の視覚 障害者が文字を学習する際にも利用可能であると考える.

\section{4-3. 今後について}

本研究では, 文字情報を触覚刺激に変換してスクロー ル呈示を行い，最適条件を探ったが，今後は，アルファ トだけではなく日本語カナ文字の認識の研究, および, 特に「D O Q や「シツ」,「アマ」「リン」など, 似通 っている文字が明確に識別できるような最適フォントの 研究等を行っていきたい.

\section{5. 結 論}

本研究において, ダイナミック型小型触覚ディスプレ イの製作を行った.アクチュエータにソレノイドを用い， ヒト触覚に最適な動作条件を求めるため実験を行った. ランドルト環の識別実験を晴眼者 10 人に対して，アルフ アベットの認識実験を視覚障害者 5 人, 晴眼者 10 人に対 して行った. 以上より実験より以下の結論を得た。

・文字情報を呈示する際は, アスペクト比は $2 ： 1$ が最適 である。

・ランドルト環の識別実験より 2 ピンの隙間 $(5 \mathrm{~mm})$ 以 下になると文字切れ目の触知が難しくなる.

・文字の間隔は, 文字の大きさの 0.5 倍のほうが 0.1 倍よ り認識度が高い.

・刺激強度が大きくなるほど認識しやすい傾向が得られた。 ・アルファベットに関しては, 簡単な基礎学習で飛躍的 に正答率が向上する。このことから本装置は文字情報 呈示装置に利用できる可能があると考える.

\section{参考文献}

1）厚生労働省 社会 - 援護局障害保健福祉部：身体障害 児・身体障害者等実態調査, 厚生労働省統計, 2006 .

2）吉崎昌彦, 新東勇, 他：小型触覚ディスプレイの試作, 電 子情報通信学会, HCS95-14, 47-52, 1995.

3）篠田裕之：皮膚感覚インターフェースの現状と展望, 第 4 回システムインテグレーション部門学術講演会, 412-413, 2003.

4) Benali-Khoudja, M., Hafez, M., et al. : Tactile interface: a state-of-the-art survey, 35th International Symposium on Robotics, 23-26, 2004.

5）坂井忠裕, 石原達哉, 他：受動的触知による新しい点字 伝達方式一文字放送点字伝達装置の試作一, 映像情報メ ディア学会誌, 52, 512-518, 1998.

6) Hafez, M. : Tactile interface: technologies, applications and challenges, The Visual Computer, 23, 267-272, 2007.

7) Wagner, C. R., Lederman, S. J. and Howe, R. D. : Design and Performance of a Tactile Shape Display Using RC Servomotors, The Electronic Journal of Haptics Research, 3, 1-6, 2004.

8）山口昌樹, 白土悟, 鹿野快男 : 触覚ディスプレイに用い る小型リニア電磁ソレノイドの基礎設計, 日本応用磁気学 会誌, 22, 945-948, 1998.

9）大頭仁, 照沼武司 : 触覚刺激によるパターン認識, 光学 技術コンタクト, 12, 11-15, 1976.

10）木塚泰弘：中中途視覚障害者の触読効率を向上させる ための総合的点字学習システムの開発, 文部省科学研究費 補助金研究成果報告書, 研究課題番号 $07401007,1995$.

11）松本悟志,他：コイル状形状記憶合金を用いた触覚ディ スプレイの評価, 人間工学, 45, 135-140, 2009.

12) Sato T., Okada Y., et al. : Distributions of sensory spots in the hand and two-point discrimination thresholds in the hand, face and mouth in dental students, Journal of Physiology, 93, 245-250, 1999.

13）岩本孝之, 篠田裕之：音響放射圧の走査による触覚ディ スプレイ, 日本バーチャルリアリティ学会論文誌, 11, 7786, 2006.

14) Vega-Bermudez, F., et al. : Human tactile pattern recognition: active versus passive touch, velocity effects, and patterns of confusion, Journal of Neurophysiology, 65, 531-46, 1991.

15）栗田正一：読みやすさの観点より求めたCRTディスプ レイに打ける日本語表示条件, テレビジョン学会誌, 39 (11), 1985.

16) Nakada, M. : Localization of a constant-touch and moving-touch stimulus in the hand, Journal of Hand Therapy, 6, 23-28, 1993.

17）嶋脇聡, 酒井直隆 : 二点識別法によるヒト手の触覚の計 測, 日本臨床バイオメカニクス学会, 24, 163-169, 2003.

18）林政一郎：触知覚における運動残効現象の研究, TVRSJ, 11, 69-76, 2006.

19）市川宏, 他：視覚障害とその代行技術, 179-181, 名古屋 大学出版会, 名古屋, 1984. 